\title{
Condições higiênico-sanitárias de uma dieta hospitalar
}

\author{
Hygienic and sanitary conditions of a hospital diet
}

Consuelo Lúcia SOUSA'

Gizella Diniz CAMPOS²

\section{R E S U M O}

Buscou-se avaliar as condições higiênico-sanitárias da dieta branda servida em um hospital geral da cidade de Belém, Pará, através da análise microbiológica de seus componentes (coliformes fecais, Staphylococcus aureus e Salmonella) e dos utensílios, equipamentos e mãos de funcionários (coliformes fecais, Staphylococcus aureus), bem como elaborar um Relatório Técnico de Inspeção da Unidade de Alimentação e Nutrição do hospital, baseado no Anexo II da Portaria 1428 de 26/11/1993, para a implantação das Boas Práticas de Fabricação. Em nenhuma das amostras foi detectada a presença de Salmonella ou Staphylococcus aureus; entretanto, os componentes da dieta, equipamentos e utensílios apresentaram $100 \%$ de coliformes fecais, assim como as mãos de duas funcionárias. Os principais pontos observados para o relatório técnico foram: padrão de identidade e qualidade, condições ambientais, instalações e saneamento, equipamentos e utensílios, recursos humanos, tecnologia empregada, controle de qualidade, garantia de qualidade, armazenagem, desinfecção e desinfestação. Através desta avaliação foram constatadas as péssimas condições higiênico-sanitárias da referida Unidade de Alimentação e Nutrição.

Termos de indexação: unidade de alimentação e nutrição, condições higiênico-sanitárias, dieta, microbiologia.

\section{A B S T R A C T}

The objectives of this work were to evaluate the hygienic and sanitary conditions of a light diet of a hospital in the city of Belém, state of Pará (Brazil), using microbiological analysis of its compounds (fecal coliforms, Staphylococcus aureus and Salmonella) and of utensils, equipment's and employees' hands (fecal coliforms, Staphylococcus aureus), and to provide an inspection technical report of the hospital Food and Nutrition Unit, according to Annex II of the 1428 th Regulation (11/26/1993) of the Ministry of Health to verify the implementation of the Good Manufacturing Practices. None of the samples presented Salmonella or

\footnotetext{
1 Departamento de Engenharia Química, Universidade Federal do Pará. Rua Marquês de Herval, 110, Pedreira, 66085-300, Belém, PA, Brasil. Correspondência para/Correspondence to: L. SOUSA.E-mail: sousa@ufpa.br

2 Especialista em Tecnologia de Alimentos, Universidade Federal do Pará.
} 
Staphylococcus aureus; however, the compounds, utensils and equipments presented $100 \%$ of fecal coliforms contamination, as well as two workers' hands. The main points identified for the technical report were: Identity and Quality Standard, Environmental Conditions, Building Maintenance and Sanitary-Conditions, Equipments and utensils, Human Resources, adapted Technology, Quality Control, Quality Assurance, Storage, Disinfection and disinfestation. It was concluded that the evaluated Food and Nutrition Unit presented very bad hygienic and sanitary conditions.

Index Terms: food and nutrition unit, sanitary and hygienic conditions, diet, microbiology.

\section{N T R O D U Ç Ã O}

Uma das vias de infecção hospitalar é a ingestão de alimentos contaminados e uma das causas dessas infecções é a falta de um programa de treinamento de boas práticas de higiene para os indivíduos que trabalham direta ou indiretamente com pessoas internadas em hospitais, devendo tal treinamento ser contínuo para todos os envolvidos com a produção de alimentos (Rêgo et al., 1997; Salles \& Goulart, 1997; Pedroso et al., 1999).

Em uma unidade hospitalar, vários critérios são estabelecidos com a finalidade principal de recuperar a saúde do paciente, enquadrando nessas exigências a dieta, a qual faz parte do seu tratamento (Manual..., 1980). Assim, os funcionários, de um modo geral, estão envolvidos nesse processo, mas aqueles que trabalham na Unidade de Alimentação e Nutrição (UAN) hospitalar têm uma responsabilidade particular, porque estão alimentando pessoas enfermas, cujo sistema imunológico pode estar debilitado.

Para o alimento se tornar fonte de saúde imprescindível ao ser humano, deve ser processado dentro de um controle de etapas, utilizando-se matéria-prima de boa qualidade, em condições higiênico-sanitárias satisfatórias, e sendo convenientemente armazenado e transportado. Quando não obedecidas essas condições, ele pode tornar-se fonte de doenças (Bobeng \& David, 1977).

A qualidade é uma característica multidimensional do alimento, sendo uma combinação de atributos microbiológicos, nutricionais e sensoriais. O seu controle em todas as etapas do processamento de alimentos tem como objetivo assegurar a qualidade, promovendo a saúde do consumidor (Bobeng \& David, 1977).

Em uma UAN hospitalar, deve-se fazer diariamente uma avaliação dos locais ou situações com maior probabilidade de agregar riscos para a saúde do internado, e estabelecer controles para estes pontos, indicando se o alimento está dentro do esperado, ou seja, dentro da conformidade pré-planejada. Esse conjunto de medidas pode ser feito através da identificação dos Pontos Críticos de Controle (Bobeng \& David, 1977; Bryan \& Lyon, 1984).

As Unidades de Alimentação que adotam um programa de controle das etapas são capazes de analisar e avaliar a preparação do alimento durante o processo, desde a matéria-prima até o produto acabado. Controlando-se a temperatura sob a qual o alimento é mantido e o tempo gasto durante seu preparo e distribuição, pode-se obter uma melhoria na qualidade e uma minimização dos riscos de um surto de origem alimentar (Cummings, 1992).

Vários autores já relataram surtos de toxinfecções alimentares ocorridos em hospitais, cuja fonte foi o próprio alimento contaminado (Sharp et al., 1979; Collier et al., 1988; Correa et al., 1990; Salles \& Goulart, 1997). Existem ainda estudos relacionando contaminação dos alimentos por utensílios usados no seu processamento e também por funcionários (Castro \& laria, 1984; Kiddy et al., 1987; Sousa \& Goulart, 1995; Salles \& Goulart, 1997; Pedroso et al., 1999).

Por isso, é importante conscientizar os responsáveis pela UAN de um hospital sobre a 
necessidade de um controle no processamento de alimentos, seguido de um acondicionamento higiênico-sanitário que atenda às características e à integridade do produto, bem como à saúde dos pacientes internados.

Tendo em vista as considerações feitas acima, o presente trabalho teve como objetivos verificar as condições higiênico-sanitárias de uma dieta branda de rotina, servida em um hospital geral da cidade de Belém, Pará, através da análise dos seus componentes alimentares e dos utensílios e equipamentos utilizados na sua preparação, comparar os procedimentos adotados na cozinha do referido hospital com os itens básicos do Manual de Boas Práticas de Fabricação, utilizando o Anexo II da Portaria 1428, de 26/11/1993, do Ministério da Saúde (Brasil, 1993), e tentar dar soluções cabíveis, baseadas no diagnóstico final, para o alimento atingir sua finalidade, que é a nutrição e preservação da saúde do consumidor.

\section{MATERIALE MÉTODOS}

As amostras foram coletadas no setor de produção de refeições de um hospital geral, com capacidade para mais de 100 leitos, situado na cidade de Belém, PA. Todas elas foram analisadas três vezes, colhidas em dias diferentes, e em cada visita era coletada apenas uma amostra de cada etapa do processo. Assim, no total, foram colhidas três amostras de cada etapa de preparação da dieta branda.

Porções de $100 \mathrm{~g}$ de todos os componentes da dieta branda (arroz, purê de abóbora, salada crua, salada cozida e carne moída) foram coletadas separadamente e assepticamente logo após o preparo. Uma amostra de água foi coletada diretamente da torneira da pia da cozinha em frasco de vidro estéril com rolha esmerilhada.

Em cada visita à cozinha, alguns equipamentos e utensílios (descascador, amassador, cortador e moedor de legumes, pranchas de altileno para carne e legumes e balcão de distribuição) que seriam utilizados na manipulação do alimento e também as mãos dos funcionários envolvidos na preparação da refeição (uma cozinheira e duas ajudantes de cozinha) foram amostrados antes do uso por fricção de um swab estéril, previamente umedecido em solução salina, em uma área conhecida (Vanderzant \& Splittstoesser, 1992).

As amostras foram acondicionadas, depois de colhidas, em caixas isotérmicas contendo gelo reciclável, e foram transportadas ao laboratório de microbiologia do Departamento de Engenharia Química da Universidade Federal do Pará logo após a coleta da última amostra, sendo analisadas no mesmo dia.

Foram pesquisados nas amostras coliformes fecais, Staphylococcus aureus e Salmonella sp. Naquelas coletadas por swab (equipamentos, utensílios e mãos de funcionários) foram feitas contagens de coliformes fecais e $S$. aureus. Todas as análises seguiram metodologias descritas no Compendium of Methods for the Microbiological Examination of Foods (Vanderzant \& Splittstoesser, 1992). Na amostra de água foi pesquisada a presença de coliformes totais, utilizando a técnica dos tubos múltiplos (American Public..., 1995).

\section{Análise das boas práticas de fabricação}

Foi elaborado um Relatório Técnico de Inspeção da UAN do hospital em estudo, baseado no Anexo II da Portaria 1428, de 26/11/93 (Brasil, 1993), para verificar a implantação das Boas Práticas de Fabricação, utilizando como instrumento de avaliação das condições higiênico-sanitárias da cozinha hospitalar observações visuais no local de preparação da dieta.

O relatório técnico foi aplicado em quatro visitas feitas à UAN. Os principais pontos observados foram: Padrão de Identidade e Qualidade (PIQ), Condições Ambientais, Instalações e Saneamento, Equipamentos e Utensílios, Recursos Humanos, Tecnologia 
Empregada, Controle de Qualidade, Garantia de Qualidade, Armazenagem, Desinfecção e Desinfestação.

As medidas de controle e monitoramento e as principais ações corretivas foram elaboradas com base nos dados da literatura (Associação Brasileira..., 1998), e nos recursos disponíveis no hospital.

A temperatura do ambiente foi medida utilizando-se termômetro de máxima e mínima (Incotherm - modelo MM 5201) colocado bem no centro da UAN hospitalar.

\section{RESULTADOSE DISCUSS ÃO}

A cozinha não apresentava áreas definidas para pré-preparo e preparo dos alimentos e nem setores distintos para carnes, cereais e vegetais. Durante a distribuição dos alimentos preparados, os componentes dos cardápios ficavam nos mesmos recipientes utilizados para cocção, exceto o purê, que era passado para outro vasilhame. Mais de 100 refeições diárias eram servidas no horário do almoço, entre $11 \mathrm{~h}$ e $12 \mathrm{~h}$, incluindo pacientes internados e funcionários. Não havia controle de temperatura em nenhuma etapa do processo, nem no momento da distribuição.

Em nenhuma das amostras analisadas dos componentes da dieta foi detectada a presença de Staphylococcus aureus ou Salmonella; porém, todas (100\%) apresentaram valores >1 $100 \mathrm{NMP} / \mathrm{g}$ de coliformes fecais (Tabela 1), número 100 vezes acima do limite permitido pela legislação vigente (Brasil, 1997), sendo, portanto, impróprias para o consumo. Estes dados são bem superiores aos obtidos por Pedroso et al. (1999), os quais avaliaram carne cozida servida em hospitais e encontraram 25\% de coliformes fecais nas amostras analisadas.

Salles \& Goulart (1997) relataram altos índices de coliformes fecais (Escherichia coli) quando analisaram leite em lactários de hospitais do município de Florianópolis, SC, tendo sido verificada contaminação por E. coli em 100\% das amostras, comprovando a ineficiência ou ausência do controle no processamento, na matéria-prima e no produto acabado.

A análise da água utilizada na preparação da dieta revelou ausência de coliformes totais em $100 \mathrm{~mL}$ da amostra (Tabela 1).

Não foi detectada a presença de $S$. aureus em equipamentos, utensílios e mãos das funcionárias (Tabela 2). Segundo Castro \& laria (1984), uma das principais fontes de contaminação de $S$. aureus em UAN são as fossas nasais dos manipuladores, e isto foi comprovado quando analisaram 78 manipuladores de alimentos em cozinhas hospitalares e observaram que $42,3 \%$ destes eram portadores nasais da referida bactéria.

Em todos os equipamentos e utensílios amostrados (100\%) foi observada a presença de coliformes fecais (Tabela 2). Esta contaminação pode ser oriunda da deficiente higienização, como também da contaminação cruzada, pois os mesmos equipamentos e utensílios eram utilizados pelos demais cozinheiros. As pranchas de altileno

Tabela 1. Resultados das análises microbiológicas dos componentes da dieta branda e da água utilizada no preparo das refeições da UAN de um hospital geral da cidade de Belém, PA.

\begin{tabular}{|c|c|c|c|c|}
\hline Amostras & $\begin{array}{l}\text { Coliformes Totais } \\
(\mathrm{NMP} / 100 \mathrm{~mL})^{*}\end{array}$ & $\begin{array}{c}\text { Coliformes Fecais } \\
(\mathrm{NMP} / \mathrm{g})^{*}\end{array}$ & $\begin{array}{l}\text { S. aureus } \\
(\mathrm{UFC} / \mathrm{g})^{*}\end{array}$ & $\begin{array}{l}\text { Salmonella } \\
(\mathrm{em} \mathrm{25g)*}\end{array}$ \\
\hline Purê de abóbora & NA & $>1100$ & $<1 \times 10^{1}$ & Ausência \\
\hline Salada crua (alface, tomate, cebola e pepino) & NA & $>1100$ & $<1 \times 10^{1}$ & Ausência \\
\hline Salada cozida (cenoura, beterraba, batata) & NA & $>1100$ & $<1 \times 10^{1}$ & Ausência \\
\hline Carne moída & NA & $>1100$ & $<1 \times 10^{1}$ & Ausência \\
\hline Água & $<3$ & NA & NA & NA \\
\hline
\end{tabular}

* média de três determinações. NA = não analisado. 
não eram separadas para legumes e carnes e entre um uso e outro eram lavadas somente com água corrente. De acordo com a Associação Brasileira... (1998), equipamentos e utensílios devem conter ausência de indicadores de contami-nação fecal.

Foi detectada a presença de coliformes fecais nas mãos de duas das três funcionárias responsáveis pelo preparo da dieta (Tabela 2). Resultados semelhantes foram encontrados por Salles \& Goulart (1997), os quais verificaram a presença de $E$. coli em mãos de manipuladores de lactários hospitalares do município de Florianópolis, SC. Deduz-se, desta forma, que houve falha de obediência aos princípios básicos de higiene, principalmente das mãos, ou houve contaminação cruzada, colocando em risco a vida dos pacientes internados no hospital.

Estudos realizados por Sharp et al. (1979), sobre surtos de origem alimentar ocorridos em hospitais na Escócia durante 1973-1977, constataram que 1119 das 1660 cozinhas de hospitais encontravam-se abaixo dos padrões requeridos pela higiene alimentar. Manipuladores de alimentos portadores de patógenos, sem hábitos adequados de higiene, foram os principais responsáveis por surtos de origem alimentar ocorridos nos Estados Unidos entre 1977 e 1982 (Bryan \& Lyon, 1984). Segundo Ungar et al. (1992), a manipulação inadequada de alimentos é a maior responsável pela maioria dos casos de doenças de origem microbiana transmitidas por alimentos.
De acordo com o relatório de inspeção sanitária, verificaram-se na linha de produção as principais operações e perigos potenciais, e a partir daí foram relacionadas medidas de controle e monitoramento e principais ações corretivas para a implementação das Boas Práticas de Fabricação (Quadro 1).

Baseado nos resultados, sugere-se:

- Adoção pelos responsáveis técnicos, de um padrão de identidade e qualidade de preparação das dietas, baseando-se nas boas práticas de produção e prestação de serviços na área de alimentos.

- Para avaliar a eficácia da linha de processo, adoção do Sistema de Análise de Perigos e Pontos Críticos de Controle (APPCC), o qual permite identificar ações que devem servir como critérios na avaliação.

- Treinamento aos que trabalham direta ou indiretamente com os alimentos, afim de instruí-los sobre os conceitos básicos de microbiologia, higiene e sanitização, levando-os a adotarem as boas práticas de produção para obtenção de serviços com qualidade.

- Realização de visitas periódicas aos fornecedores, para ter segurança da aquisição de matérias-primas devidamente registradas e inspecionadas por órgãos competentes.

- Uso de sanitizantes adequados para higienização de equipamentos e utensílios utilizados na produção das dietas.

Tabela 2. Resultados das análises microbiológicas de equipamentos, utensílios e manipuladores de alimentos que serão utilizados no preparo de dieta branda da UAN de um hospital geral da cidade de Belém, PA.

\begin{tabular}{lcc}
\hline Equipamentos/utensílios/ manipuladores & Coliformes Fecais (presença/ausência)* & S. aureus (presença/ausência)* \\
\hline Descascador de legumes & Presença & Ausência \\
Amassador de legumes & Presença & Ausência \\
Cortador de legumes & Presença & Ausência \\
Moedor de legumes & Presença & Ausência \\
Pranchas de altileno para carne e legumes & Presença & Ausência \\
Balcão de distribuição & Presença & Ausência \\
Mãos de funcionários** & Presença & Ausência \\
\hline
\end{tabular}

* média de três determinações; ** valor referente a 2 de 3 funcionários amostrados. 
Quadro 1: Principais operações e perigos potenciais observados na linha de processo das preparações de dietas brandas do hospital estudado, com medidas de controle e monitoramento e ações corretivas.

\begin{tabular}{|c|c|c|c|}
\hline Operação & Perigos Potenciais & Medidas de Controle/Monitoramento & Ações Corretivas \\
\hline Compras & $\begin{array}{l}\text { Aquisição de matérias-primas } \\
\text { de fonte não segura }\end{array}$ & $\begin{array}{l}\text { Visita aos fornecedores com } \\
\text { preenchimento do relatório de visita }\end{array}$ & $\begin{array}{l}\text { Exclusão dos fornecedores } \\
\text { que não atendam aos } \\
\text { requisitos exigidos }\end{array}$ \\
\hline Recepção & $\begin{array}{l}\text { Utilização de equipamentos que } \\
\text { apresentem más condições de } \\
\text { higiene; contaminação cruzada }\end{array}$ & $\begin{array}{l}\text { Verificação da validade e condições das } \\
\text { embalagens no ato da entrega; verificação } \\
\text { das práticas de higiene de equipamentos, } \\
\text { utensílios e manipulador; controle de } \\
\text { temperatura }\end{array}$ & $\begin{array}{l}\text { Devolução do produto } \\
\text { que não atenda os } \\
\text { requisitos exigidos }\end{array}$ \\
\hline Pré-preparo & $\begin{array}{l}\text { Contaminação cruzada; } \\
\text { multiplicação de bactérias }\end{array}$ & $\begin{array}{l}\text { Verificação das condições de higiene das } \\
\text { superfícies de contato; rapidez no processo }\end{array}$ & $\begin{array}{l}\text { Orientação ao funcionário; } \\
\text { correta higiene de } \\
\text { equipamentos, utensílios e } \\
\text { mãos; aceleração do } \\
\text { processo }\end{array}$ \\
\hline $\begin{array}{l}\text { Armazenamento } \\
\text { sob refrigeração }\end{array}$ & $\begin{array}{l}\text { Contaminação cruzada; } \\
\text { multiplicação e sobrevivência } \\
\text { de bactérias patogênicas; } \\
\text { vencimento do prazo de } \\
\text { validade }\end{array}$ & $\begin{array}{l}\text { Definição de espaços específicos para } \\
\text { cada gênero de produto; controle da } \\
\text { temperatura de freezers e câmaras } \\
\text { frigoríficas; controle de prazo de validade }\end{array}$ & $\begin{array}{l}\text { Utilização dos produtos } \\
\text { com maior tempo de } \\
\text { refrigeração; identificação } \\
\text { dos recipientes; desprezo } \\
\text { do produto quando } \\
\text { vencido; manutenção da } \\
\text { temperatura }\end{array}$ \\
\hline Resfriamento & $\begin{array}{l}\text { Multiplicação de bactérias através } \\
\text { do exsudato; contaminação } \\
\text { cruzada; sobrevivência de } \\
\text { bactérias }\end{array}$ & $\begin{array}{l}\text { Monitoramento de tempo/temperatura; } \\
\text { verificação da prática de higiene e } \\
\text { sanitização }\end{array}$ & $\begin{array}{l}\text { Higiene das vitrines de } \\
\text { exposição; utilização de } \\
\text { vitrine de resfriamento } \\
\text { rápido; utilização de } \\
\text { recipientes exclusivos para } \\
\text { cada matéria-prima }\end{array}$ \\
\hline Preparo & $\begin{array}{l}\text { Contaminação cruzada; multipli- } \\
\text { cação de bactérias }\end{array}$ & $\begin{array}{l}\text { Monitoramento de tempo/temperatura; } \\
\text { rapidez no processo }\end{array}$ & $\begin{array}{l}\text { Aceleração do processo; } \\
\text { higiene de utensílios, } \\
\text { equipamentos e mãos }\end{array}$ \\
\hline Distribuição & Multiplicação bacteriana & Monitoramento de tempo/temperatura & Consumo imediato \\
\hline $\begin{array}{l}\text { Higiene dos } \\
\text { equipamentos e } \\
\text { utensílios }\end{array}$ & $\begin{array}{l}\text { Contaminação cruzada; } \\
\text { permanência de resíduos } \\
\text { orgânicos }\end{array}$ & $\begin{array}{l}\text { Verificação do processo de higienização; } \\
\text { utilização de cloro }\end{array}$ & $\begin{array}{l}\text { Adequação do processo } \\
\text { de higienização }\end{array}$ \\
\hline Higiene das mãos & $\begin{array}{l}\text { Contaminação durante } \\
\text { o processo (coliforme fecal) }\end{array}$ & $\begin{array}{l}\text { Verificação do processo de higiene do } \\
\text { manipulador }\end{array}$ & $\begin{array}{l}\text { Orientação ao manipulador } \\
\text { fornecimento de condições } \\
\text { adequadas para realização } \\
\text { das boas práticas de } \\
\text { higiene }\end{array}$ \\
\hline $\begin{array}{l}\text { Higienização dos } \\
\text { Vegetais }\end{array}$ & $\begin{array}{l}\text { Permanência de patógenos } \\
\text { iniciais }\end{array}$ & $\begin{array}{l}\text { Utilização de equipamento (fita) para } \\
\text { titulação e utilização de cloro; verificação e } \\
\text { utilização das práticas de higiene }\end{array}$ & $\begin{array}{l}\text { Orientação sobre a prática } \\
\text { correta de higiene; } \\
\text { utilização de solução de } \\
\text { hipoclorito }\end{array}$ \\
\hline
\end{tabular}


- Higienização das mãos com sanitizantes, utilizando critérios.

- Controle da temperatura durante o processo de produção e armazenamento da matéria-prima.

- Supervisão de todas as etapas do processo.

- Implantação do sistema de Controle de Qualidade, o qual é de suma importância para a UAN deste hospital, sendo necessário, antes de tudo, a elaboração do Manual de Boas Práticas do Serviço.

- Designação de um responsável pela supervisão e monitoramento e pelas ações corretivas a serem tomadas, ação de fundamental importância para que seja assegurada a qualidade microbiológica das dietas analisadas.

O responsável, ao tomar essas providências, com certeza, estará garantindo a qualidade de seus serviços aos pacientes internados e prevenindo o risco de toxinfecção alimentar.

Sousa \& Goulart (1995), quando avaliaram a implantação do sistema análise de riscos e pontos críticos de controle durante as operações com preparações à base de carne bovina em uma cozinha hospitalar, estabeleceram como pontos críticos: recepção da matéria-prima, pré-preparo, armazenamento antes e após o pré-preparo, adição de tempero, cocção, fatiamento, sistema de manutenção do calor após cocção e porcionamento e sistema de manutenção do calor na distribuição. Além disso, eles demonstraram que muito precisa ser feito, principalmente em UAN hospitalares.

\section{CONCLUSÃO}

Os resultados obtidos permitem concluir que as condições higiênico-sanitárias da UAN do hospital estudado encontravam-se inadequadas; que os equipamentos e utensílios utilizados na elaboração da dieta branda representaram pontos de risco de contaminação, por isso requerem maior ênfase quanto à sua higienização, para reverter as condições insatisfatórias detectadas; e que os dados deste trabalho oferecem subsídios para medidas corretivas na preparação da dieta estudada e reiteram a necessidade de estabelecimento de programas de educação continuada dos manipuladores envolvidos direta ou indiretamente com a produção de alimentos.

\section{REFERÊ NCIAS BIBLIOGRÁFICAS}

AMERICAN PUBLIC HEALTH ASSOCIATION. Standard Methods for the Examination for Water and Wastewater. 19.ed. Washington DC: APHA, 1995. 1100p.

ASSOCIAÇÃO BRASILEIRA DAS EMPRESAS DE REFEIÇÕES COLETIVAS. Manual de práticas de elaboração e serviço de refeições para coletividades. 4.ed. São Paulo : [s.n.], 1998. 195p.

BOBENG, B.J., DAVID, B.D. HACCP: models for quality control of entrée production in food service systems. Journal of Food Protection, Ames, v.40, n.9, p.632-638, 1977.

BRASIL. Ministério da Saúde. Portaria no 1428, de 26 de novembro de 1993. Aprova Regulamento Técnico para Inspeção Sanitária de Alimentos. Diário Oficial da União, Brasília, DF, 2 Dez. 1993.

BRASIL. Ministério da Saúde. Portaria no 451, de 19 de setembro de1997. Estabelece critérios e padrões microbiológicos para alimentos. Diário Oficial da União, Brasília, DF, n.182, 22 set. 1997. Seção 1, p.21005.

BRYAN, F.L., LYON, J.B. Critical control points of hospital foodservice operations. Journal of Food Protection, Ames, v.47, n.12, p.950-963, 1984.

CASTRO, M.M.M.V., IARIA, S.T. Staphylococcus aureus enterotoxigênico no vestíbulo nasal de manipuladores de alimentos em cozinhas hospitalares do Município de João Pessoa, PB. Revista de Saúde Pública, São Paulo, v.18, n.3, p.235-245, 1984.

COLLIER, P.W., SHARP, J.C.M., Mac LEOD, A.F., FORBES, G.I., MACKAY, F. Food poisoning in hospitals in 
Scotland: 1978-1984. Epidemiology and Infection, Cambridge, v.101, n.5, p.661-667, 1988.

CORREA, C.M.C., TIBANA, A., GONTIJO-FILHO, P.P. Avaliação de vegetais como fonte de infecção por Pseudomonas aeruginosa para pacientes hospitalizados: 1. nível de contaminação de alimentos servidos aos pacientes. Revista de Microbiologia, São Paulo, v.2, n.3, p.238-242, 1990.

CUMMINGS, A.R. Quality control principles: applications in dietetic practice. Journal of the American Dietetic Association, Chicago, v.92, n.4, p.427-428, 1992.

KIDDY, K., JOSSE, E., GRIFFIN, N. An outbreak of serious Klebsiella infections related to food blenders. Journal of Hospital Infection, New York, v.9, n.2, p.191-193, 1987.

MANUAL DE DIETAS DO COMPLEXO DO HC. São Paulo : Universidade de São Paulo, 1980. 122p. (Hospital das Clínicas da Faculdade de Medicina).

PEDROSO, D.M.M., IARIA, S.T., GAMBA,R.C., HEIDTMANN, S., RALL, V.L.M. Critical control points for meat balls and kibbe preparations in a hospital kitchen. Revista de Microbiologia, São Paulo, v.30, n.4, p.347-355, 1999.

RÊGO, J.C., GUERRA, N.B., PIRES, E.F. Influência do treinamento no controle higiênico-sanitário de unidades de alimentação e nutrição. Revista de Nutrição da PUCCAMP, Campinas, v.10, n.1, p. 50-62, 1997.

SALLES, R.K., GOULART, R. Diagnóstico das condições higiênico-sanitárias e microbiológicas de lactários hospitalares. Revista de Saúde Pública, São Paulo, v.31, n.2, p.131-139, 1997.

SHARP, J.C.M., COLLIER, P.W., GILBERT, R.J. Food poisoning in hospital in Scotland. Journal Hygiene, London, v.83, n.2, p.231-236, 1979.

SOUSA, A.A., GOULART, R. Operações com carne bovina em cozinha hospitalar: análise de riscos e pontos críticos de controle. Higiene Alimentar, São Paulo, v.9, n.37, p.32-37, 1995.

UNGAR, M.L., GERMANO, M.I.S., GERMANO, P.M.L. Riscos e conseqüências da manipulação de alimentos para a Saúde Pública. Higiene Alimentar, São Paulo, v.6, n.21, p.14-16, 1992.

VANDERZANT, C., SPLITTSTOESSER, D.F. Compendium of methods for the microbiological examination of foods. 3.ed. Washington DC : American Public Health Association, 1992. 1219p.

Recebido para publicação em 20 de outubro de 2000 e aceito em 7 de fevereiro de 2002. 